\title{
English as a Lingua Franca in Europe: the Identification of L1 and L2accents
}

\author{
A Multifactorial Analysis of Pan-European Experimental Data \\ Gitte Kristiansen, Eline Zenner and Dirk Geeraerts \\ Universidad Complutense de Madrid /University of Leuven
}

\begin{abstract}
While empirical research on attitudes towards languages and linguistic varieties has become increasingly popular from the 1960s onwards (e.g. Lambert at al. 1960), experimental investigations into the ability to correctly identify the origin of speakers are in comparison still relatively scarce. We know that the ability to correlate a stretch of uncategorised speech (token) with a series of models (types) is experientially acquired in early childhood (e.g. Kristiansen 2010), but how similar are those abilities in adulthood and across European nations? English as a Lingua Franca (ELF) has become an integral part of the linguistic reality in Europe (and of the linguistic scenario in the entire world) (e.g. Jenkins, Baker \& Dewey 2018). Whenever we communicate with anyone who is not a speaker of our own native language in any European country, most of the time we communicate in English. But does our L1 accent still shine through? Will we be recognised (and in most cases probably also) stereotypically judged on the basis of just a short stretch of speech when we communicate in ELF? In Part I of this paper we outline the design of the first large-scale pan-European project on L1 and L2 identifications of English as a Lingua Franca in Europe, including 785 respondents from 8 countries. Exploratory analyses confirm the hypothesis that statistically significant asymmetries would show up across different European countries or regions. In Part II of this paper we then aim to explain these asymmetries through a multifactorial statistical analysis (Geeraerts, Grondelaers \& Speelman 1999; Tagliamonte \& Baayen 2012; Speelman, Heylen, Geeraerts 2018).
\end{abstract}

\section{Keywords}

English as a Lingua Franca, language awareness and identification, Cognitive Sociolinguistics, inferential statistics. 


\section{Introduction}

According to Ethnologue 2017, 20th edition, English is the third largest language in the world, spoken by approximately 400 million first-language speakers, only outnumbered by Chinese, (Mandarin including Standard Chinese, 960 million) and Spanish (570 million). The expansion of English has been illustrated by Kachru's $(1985,1992)$ well-known threelayered representation of Concentric Circles. Although this model has received quite some criticism due to its its ideological L1-centrism, the sharp distinction between "inner" and "outer" circles, and the lack of flexibility to accommodate variation and change in the three groups (see e.g. Graddol 1997; Modiano 1999; Seidlhofer 2002; Yano 2001; Kirkpatrick 2014; and Polzenhagen \& Dirven 2008 for an overview of the debate, building on Geeraerts 2003), the model is still often used for ease of reference, as it conveniently describes the historic three-stage diasporic expansion of English. The model involves an Inner Circle (English as a native 'norm-providing' language, comprising e.g. British, American, Australian), an Outer Circle (where English is an official second 'norm-developing' language, like in Singapore, India or Nigeria) and an Expanding Circle (comprising countries where English is a foreign 'norm-dependent' language with no official status, like in most countries in Europe). Particularly striking is the fact that the number of Expanding Circle speakers adds up to over one billion speakers, near double the number of Inner and Outer Circle speakers combined. In fact, if we consider the Centripetal Model (Modiano 1999), one of the alternatives provided for Kachru's L1-centric model, that proposes replacing the Inner Circle native speakers with proficient speakers of International English, the distinction between 
native and non-native is neutralised in the sense that speakers of English as a Lingua Franca need not necessarily perceive either native speakers or native teachers as superior, in spite of some obvious linguistic advantages (see e.g. Seidlhofer 2004; House 2009 for further debate on ELF as a sui generis variety, and see Seargeant 2017 for an account against the background of Brexit). One of the questions in this respect concerns the attitudes of nonnative speakers towards this democratic conception of ELF, detached from native speaker norms: to what extent do non-native speakers consider themselves as "perforce deficient communicators who are perpetually, agonizingly, chronically struggling, like Sisyphus and his stone, to ascend the steep incline of their 'interlanguage', the goal being the promised land of 'target competence', that hallowed place reserved for the fabled and idealized native speakers?" (Firth 2009: 151).

This issue of attitudes towards varieties of English (see e.g. Zhang \& Hu 2008; McKenzie 2008; Jenkins 2007, 2009; Young \& Walsch 2010; Dewey 2011; Eisenchlas \& Tsurutani 2011 for non-native speaker attitudes mainly focusing on L1 varieties and e.g. Lindemann 2005 for the native speaker perspective) ties in with the broader sociolinguistic research on attitudes that became popular in the 1960s (e.g. Lambert et al. 1960; Garrett et al. 2003; Giles and Rakić 2014) and still constitutes a very active field of research. For instance, one of the hot topics in current perception and attitude research is the extent to which implicit or explicit elicitation techniques do the best job when it comes to triggering attitudes from respondents (e.g. Grondelaers \& Kristiansen 2013; Rosseel 2017). Also often relying on these research traditions are studies on the (mutual) intelligibility of varieties of English (e.g. 
Pickering 2006 for an overview paper and see Jenkins 2000 for the Lingua Franca Core). However, the growing interest in the evaluation of non-native varieties does not yet go hand in hand with an interest in the identifiablity of non-native accents. Experimental investigations on the ability to correctly identify speakers' origins are still relatively scarce, not only in research on English as a Lingua Franca (see Jarvella et al. 2002 and Scales et al. 2012 for exceptions), but also in the broader sociolinguistic framework (though see Purnell et al. 1999; Kristiansen 2003, 2010; McKenzie 2015; Carrie \& McKenzie 2017).

In this article we ask the question whether in European countries native and non-native speakers are still identified (and hence stereotypically evaluated in terms of attitudes) when communicating in English (cf. Kristiansen 2001, 2003). Do their L1 accents shine through so that listeners pinpoint the speaker's origin and set the evaluational mental machinery in motion? Is ELF a liberating tool for interpersonal communication, similar to the standard variety of a language, or does it still carry the links with social identities that social and regional varieties do? In light of the broader discussion of the sui generis state of English as a Lingua Franca, this question needs to be addressed. This is the goal of the present contribution.

We here report on the results of an identification experiment conducted as part of a broader research project on the identification and evaluation of $L 2$ accents of English, funded by the Spanish Ministry of Science and Innovation (FFI2010-19395) ${ }^{1}$.

\footnotetext{
${ }^{1}$ The PI of the project was Gitte Kristiansen, and other members from the Universidad Complutense de Madrid included Enrique Bernárdez Sanchis and Paloma Tejada Caller. The external members were Dirk
} 
The main research questions for the project are:

a) in general, does L2 lectal identification take place above chance when communicating through ELF?

b) more specifically, if we zoom in on European L2 varieties of English, do systematic differences show up in identificational competence (and in social stereotyping) across European countries, and if so, how could they be explained?

The Cognitive Sociolinguistic background to these research questions is summarized in Section 2 of this paper. Next, the experimental design is presented in Section 3, together with the first exploratory analyses of the experimental task. Section 4 and Section 5 then present the multifactorial inferential analyses, respectively presenting the predictor variables that are included to help explain the variation attested in the identification competence of the respondents in Section 3 and the results. Section 5 then presents the results through mixed effect logistic regression models, conditional inference trees and random forests: can we explain why in some countries lectal awareness is much more refined than in other European countries?

\section{Theoretical background: lectal varieties as socially diagnostic triggers of meaning}

According to the main tenets of Cognitive Linguistics - and usage-based linguistics in general

- cognitive and cultural schemas build up from early childhood onwards to result in

Geeraerts (University of Leuven, Belgium), Raphael Berthele (University of Fribourg, Switzerland) and Lynn Clark (formerly University of Edinburgh, now University of Canterbury, New Zealand). 
generalisations over usage-based events. In the case of phonetics, this means that phonetic details are not discarded when phonemic categorisation is effected (Bybee 2001), but stored and put to usage for purposes that are not restricted to understanding what is being said, but also to how it is being said, e.g. for purposes of social categorisation (Kristiansen $2003,2008)$. In fact, in the context of child language acquisition, an empirical study in the community of Madrid showed that children's perception of regional origin when listening to different accents went from very scarce knowledge at the age of 6-7 to much more refined patterns of knowledge at the age of 8-9, reaching fairly high levels of accuracy in early adolescence at the age of 12-13 (Kristiansen 2010). Hence, accents are socially diagnostic because correct identification implies the ability to correlate uncategorised stretches of speech (tokens) with gradually built-up schemas (types), and the crucial age spans run between 8-12 years. The lectal schemata that we build up in childhood are thoroughly grounded in usage-based experience.

Next, if we asume that most categories in language and in our social and natural world, constitute prototype categories (Rosch 1973, 1978; Geeraerts 1983, 1985; Taylor 1989), a natural next step is to consider accents and dialects and other lectal varieties also in terms of prototype categories (Kristiansen 2001, 2003, 2006, 2008; Polzenhagen \& Xia 2015; Marzo et al. forthc.). This is precisely where the link with the psychological attributes associated with social groups comes in to form part of the perception frame. If prototype categories have central images, social groups will be prototypically associated with a certain speech style, a certain ideology, a certain physical appearance and a certain type of social 
behaviour. This metonymic link between social and linguistic stereotypes (Kristiansen 2003) forms part of the social meaningfulness of linguistic varieties: speech styles work as useful cognitive reference point constructions that allow us to navigate efficiently in a complex social world. Linguistic stereotypes, in the sense of a unique cluster of features pointing in an exclusive - and hence identifying - manner to a specific social group and the psychological attributes associated with the group serve to quickly and efficiently categorize and classify our social environment, with stereotyping as a potential negative side effect. If social stereotypes are automatically evoked through lectal identification when speakers of ELF communicate, then the relative degree of accuracy regarding correct identification is definitely an issue of interest in the scholarly debate on ELF, and an issue that we address in this article by means of a large-scale empirical study.

\section{Identification experiment: design and exploration}

This section consists of two main parts. Part one presents the design of the identification experiment, where 785 participants from eight countries were presented with twelve accent varieties of English. We first describe the experimental task, the design of the stimuli and the selection of respondents. Part two proceeds to an exploration of the identification competence of the respondents, looking for the main patterns across stimuli and participants. As expected, clear asymmetries are attested. This observation forms the basis of Section 4 and 5, which present a multifactorial analyses aimed at explaining the attested differences between stimuli and country of residence of the participants in the experiment. 


\subsection{Design}

In terms of stimuli, for both the evaluation task and the identification part of the experiment, participants were presented with speech samples from twelve different speakers (verbal guise; see Cooper 1975), who read the same English text of approximately 30 seconds (see below): four native accents (General American, Standard Southern British English, Scottish, Australian) and eight non-native accents (Spanish, French, German, Swiss German, Netherlandic Dutch, Belgian Dutch, Danish, Polish). The twelve speech fragments used as stimuli were selected from a sample of 115 digital recordings of female native speakers of the twelve varieties, aged 18-25. In the case of non-native speakers we selected those with an attested upper-intermediate level of English so as to render the recordings fluid while still allowing the speakers' native accents to shine through. In turn, levels of L2 accentedness were rated as intermediate by panels of native speakers (by native linguists in the case of Swiss German, Scottish and Danish), although some variation is still found (see Section 4 and Section 5). Although recently new tools for measuring (foreign or native) phonetic distance with respect to a standard have been developed (e.g. Levenshtein distances, cf. Wieling et al. 2014; Jurado \& Kristiansen to appear), we opted for prototypicality judgments for this experiment: from the sample of 115 recordings, the 12 speech fragments that the panel of native speakers of the respective varieties judged to best represent the twelve L1 and L2 varieties of English thus constitute the collection of stimuli the respondents were exposed to. 
The text we designed was short (keeping the duration of each recording below 30 seconds) but packed with phonetic variables and different mood structures, so as to also trigger variety-specific intonation patterns. The text simulated a short message left on an answering machine:

Hi. It's me. Listen, I don't want to sound dramatic, but I think we'd better discuss the problem now! I know, it's a little bit of a hassle, but it's a difficult situation: a lot of money is at stake here! So let's try to get started as soon as possible. How about the place just down the road? At half past four? Or do you prefer later on? Oh! And if we close the deal tonight we might like to stay and go out for a drink and a dance.

The experiment consisted of three successive tasks.

Task 1: Participants were first asked to evaluate 12 different ( 4 native and 8 non-native) speakers reading the same text in Standard English on a five point 8 dimensional semantic differential scale. For each speech fragment, the respondents were asked to rate the extent to which they found the speaker intelligent, hard-working, confident, trustworthy, friendly, helpful, successful and polite. An analysis of the answers to this evaluation task falls outside the scope of this paper.

Task 2: The speech fragments were played again, this time in a different randomised order to avoid priming effects from Test 1. Participants were then asked to locate each of the 12 speakers geographically on a 24-option response form ("which country is this speaker from?"). The 24 options were presented in the same order to all participants for every fragment:

American, New Zealand English, British, Scottish, South African English, Australian (Native Englishes) 
Finnish, Hungarian, Estonian (Finno-Ugric)

German (from Germany), Swiss German, Netherlandic Dutch, Belgian Dutch (West

Germanic)

Russian, Czech, Polish, Croatian (Slavic)

Spanish, Portuguese, French, Italian (Romance)

Norwegian, Danish, Swedish (North Germanic)

To make the selection much more difficult - and thus much more realistic - we included options representing the main language groups in Europe, and twice as many possibilities as those that were actually included in the experiment. In the overview above, we highlight the 12 accents that were actually represented in the tests.

Task 3: Respondents were asked to fill in a personal data questionnaire, with thirteen targeted questions of sociolinguistic interest (age, gender, country of origin, parents' country of origin, parents' socio-economic status, mother tongue, language skills, parents' mother tongues, years spent abroad, years spent in country of origin, etc.).

Respondents were selected from the humanities and social sciences departments at the following universities and undergraduate institutions, where the experiments were conducted: Universidad Complutense de Madrid (Spain), Ludwig Maximilian University (Munich, Germany), the University of Leuven (Belgium), Jagiellonian University (Krakow, Poland), Tischner University (Krakow, Poland), Vrije Universiteit Amsterdam (the Netherlands), Universiteit van Amsterdam (the Netherlands), University of Fribourg (Switzerland), Baden Kantonsschule (Switzerland), University of Copenhagen (Denmark), 
Dronninglund Gymnasium and Media College Aalborg (Denmark), University of Lille

(France), University of Canterbury (New Zealand). In all the countries, except for New Zealand, the tests were administered by the PI (with the help of Dirk Geeraerts and Raphael Berthele in the case of Belgium, the Netherlands and Switzerland) so as to ensure that exactly the same instructions were given and that the same procedures were followed. In the case of New Zealand, Lynn Clark was in charge of running Test 2 in a group of over 50 students ${ }^{2}$.

As such, the initial set of respondents consists of at least 100 test subjects per country from 7 European countries: France $(n=100)$, Germany $(n=104)$, Spain $(n=100)$, Switzerland $(n$ $=100)$, Belgium (100), the Netherlands $(n=114)$, and Poland $(n=103)$. In the case of Denmark there were two samples, one including students at a pre-university level $(n=100)$, the other consisting of undergraduate university students $(n=52)$. As the pre-university level students fall in the same age category of university students from some of the other countries in the sample (e.g. Belgium), we aggregate over these two sets of Danish respondents in the analyses.

Based on the information the students provided in the questionnaire, a total of 88 respondents were removed from the analyses. These include students with another mother

\footnotetext{
${ }^{2}$ Needless to say we are immensely grateful to the teachers who generously lent us an instrumental hand in order to access their institutions (including Hans Jörg Schmid, Elzbieta Tabakowska, Maarten Lemmens, Peter Harder, Elisabeth Engberg-Pedersen, Mike Hannay, Anne-Mie Nielsen and many other scholars), and above all to the many hundreds of students in the eight Euopean countries and in New Zealand who volunteered to participate in the experiment.
} 
tongue than expected for the country of residence $(n=34)$, students with a mismatch between country of origin and country of residence mitigated by the number of years of residence $(n=23)$, students who did not provide information on the socio-economic status of their parents $(n=16)$, and students under $17(n=1)$ and students over 30 years old $(n=$ 14). Additionally, as the present study only focuses on the identification competence of nonnative speakers of English, the 50 New Zealand participants are excluded from our analyses. This still leaves us with a more than adequate number of respondents: below, we analyze the responses of 785 students from eight countries, as listed in Table 1 . Table 1 further includes the mean age of respondents per country (with standard deviation) and the number of male and female students. The same gender imbalance can be found in each country, with a majority of female students. This should however not harm the analyses as we still have a sufficiently large number of men to look for significant gender differences.

\begin{tabular}{|l|c|c|l|}
\hline Country of residence & N students & Mean age (with SD) & Gender \\
\hline Belgium (Dutch-speaking part) & 95 & 18.4 (SD 1.19) & $\mathrm{F}=78, \mathrm{M}=17$ \\
\hline Denmark & 136 & 20.0 (SD 2.5) & $\mathrm{F}=83, \mathrm{M}=53$ \\
\hline France & 98 & 18.5 (SD 1.2) & $\mathrm{F}=74, \mathrm{M}=24$ \\
\hline Germany & 99 & 21.6 (SD 2.5) & $\mathrm{F}=63, \mathrm{M}=36$ \\
\hline The Netherlands & 99 & 21.2 (SD 2.6) & $\mathrm{F}=65, \mathrm{M}=34$ \\
\hline Poland & 99 & 22.3 (SD 1.9) & $\mathrm{F}=79, \mathrm{M}=20$ \\
\hline Spain & 91 & 20.4 (SD 2.4) & $\mathrm{F}=70, \mathrm{M}=21$ \\
\hline Switzerland (German speakers) & 68 & 21.1 (SD 3.0) & $\mathrm{F}=44, \mathrm{M}=24$ \\
\hline
\end{tabular}

Table 1. Overview of respondents per country, with mean age, and number of female and male students 
In terms of procedure, the students were duly informed before the tests began about ethical issues: they were told that the investigation in question would be about "research in linguistics", that if they chose to volunteer and participate they would listen to 12 different speech fragments and fill in two response forms about them, that afterwards they would fill in a completely anonymous and brief sociolinguistic questionnaire and that the results would only be used and published in terms of anonymous data and solely for scientific purposes.

\subsection{Exploration}

In this section, we explore the effect of the country of identified (stimulus) and identifier (respondent) on the identificational success through descriptive statistics. This mean that we work with a two-tiered perspective on identification: on the one hand there is an identifier, on the other an identified. We take the two perspectives in turn. Identificational success is measured strictly: an answer is only considered correct when respondents select the precise region for the stimulus. A more lenient alternative is to also consider "almost correct" answers as correct, for example considering Italian, Portuguese and Spanish as "correct" answers for the French stimulus. Figure 1 reveals the difference between the two perspectives, providing a visual representation depicting the ranking of the identifiers in terms of the number of correct answers ${ }^{3}$.

\footnotetext{
3 The same abbreviations are used throughout: DM (Danish), FR (French), SP (Spanish), PL (Polish), GE (German), SW (Swiss German for identified, German-speaking Swiss for identifier), BE (Belgian Dutch), NL (Netherlandic Dutch), US (US English), AUS (Australian English), BRI (Standard Southern British English), SCO (Scottish English).
} 

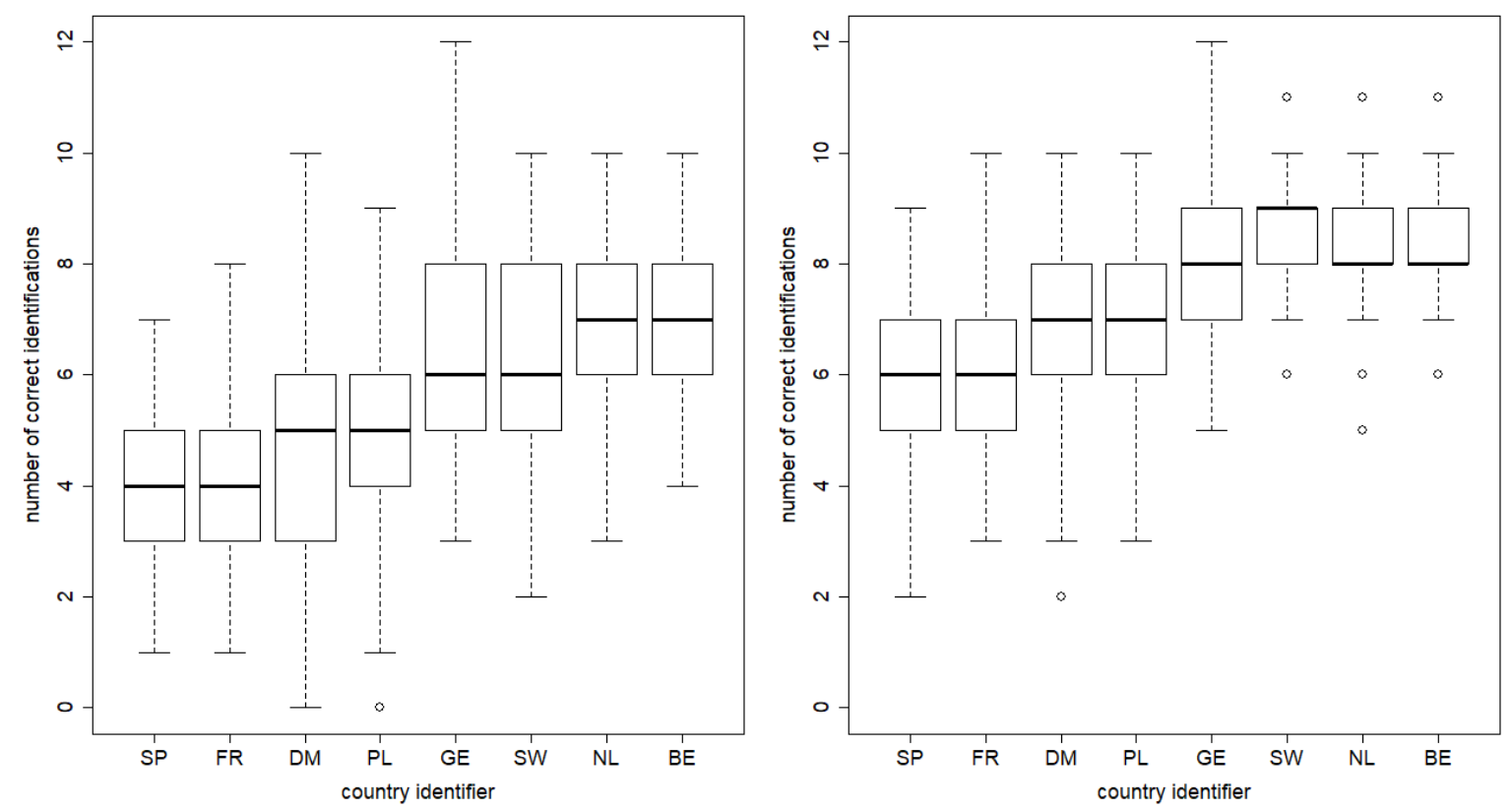

Figure 1. Ranking of best identifiers (left panel uses strict correction key, right panel uses lenient correction key)

As can readily be observed, the four mid-European West-Germanic countries come in as clear winners when it comes to identificational dexterity. The Belgian Dutch natives on average were able to identify an impressive 7.1 accents out of 12 possibillities on a 24 option response form (SD 1.22). The Dutch are in their heels with 6.99 (SD 1.48) and next come the Swiss (mean 6.4, SD 1.95) and the Germans (mean 6.3, SD 1.75), the Poles (mean 4.9, SD 1.87) and the Danes (mean 4.6, SD 2.0). France (mean 3.9, SD 1.2) and Spain (mean 3.8, SD 1.38) both produced the lowest scores, close to only 4 correct answers out of 12 .

However, reversing the perspective to the identified (plotting out how many of the 785 respondents correctly identify a given stimulus), we see that the best identifiers from Figure 
1 are not necessarily at the same time those who are identified the best. Nor are the worst identifiers from Figure 1 the least identified. As Table 2 reveals, in spite of the fact that the French and the Spanish were less agile as identifiers of their European peers, French and Spanish were amongst the best identified accents in the sample.

\begin{tabular}{|l|c|c|c|c|}
\hline Identifier (stimulus) & correct & not.corr & NA & $\begin{array}{c}\text { percentage correct } \\
\text { (NA excluded) }\end{array}$ \\
\hline US & 669 & 116 & 0 & $85.2 \%$ \\
\hline SCO & 596 & 188 & 1 & $76.0 \%$ \\
\hline BRI & 581 & 204 & 0 & $74.0 \%$ \\
\hline FR & 566 & 217 & 2 & $72.3 \%$ \\
\hline SP & 412 & 371 & 2 & $52.6 \%$ \\
\hline AUS & 325 & 459 & 1 & $41.5 \%$ \\
\hline NL & 272 & 510 & 3 & $34.8 \%$ \\
\hline GE & 251 & 531 & 3 & $32.1 \%$ \\
\hline DM & 193 & 589 & 3 & $24.7 \%$ \\
\hline BE & 168 & 614 & 3 & $21.5 \%$ \\
\hline SW & 119 & 664 & 2 & $15.2 \%$ \\
\hline PL & 109 & 673 & 3 & $13.9 \%$ \\
\hline
\end{tabular}

Table 2 Ranking of best identifiers

We observe that General North American English is the accent that is by far the variety which is identified the best (669 correct identifications), followed by Scottish, Standard Southern British English, French, Spanish and Australian. It is noteworthy, in fact, to see that Australian, a native variety of English, is outranked by French and Spanish, the southern Romance languages in the sample. Next come the four best identifiers, the Netherlands, Germany, Belgium and Switzerland, and at the end, Denmark and Poland. 
The results above demonstrate clear asymmetries in the identification of the various stimuli and in the identification competence of the various identifiers. When we cross identifiers and identified, interesting asymmetries can be attested. In what follows we turn to the inferential statistical analyses in an attempt to explain the interplay between identifier, identified and identification competence.

To provide an example of how the different identifiers identified one of the best-known accents, namely Scottish, Table 3 reflects the 629 correct identifications of the Scottish accent as distributed over the 9 groups:

\begin{tabular}{|l|c|c|c|}
\hline Identified = SCO & correct & not.corr & percentage correct \\
\hline NL & 98 & 1 & $99.0 \%$ \\
\hline BE & 93 & 2 & $97.9 \%$ \\
\hline DM & 113 & 23 & $83.1 \%$ \\
\hline GE & 77 & 22 & $77.8 \%$ \\
\hline SW & 52 & 16 & $76.5 \%$ \\
\hline PL & 66 & 32 & $67.3 \%$ \\
\hline FR & 61 & 37 & $62.2 \%$ \\
\hline SP & 36 & 55 & $39.6 \%$ \\
\hline
\end{tabular}

Table 3. Scores of correct identification of the Scottish accent

As we also kept track of all the wrong answers, we know how the Scottish accent was erroneously identifed. Although 14 respondents curiously enough confounded the Scottish accent with German, the rest were all near hits, i.e. native accents such as Standard Southern British $(n=37)$, Australian $(n=28)$ and New Zealand Englishes $(n=14)$. We therefore decided to process results for the near hits, or lenient results, i.e. those cases in 
which a respondent failed to choose the correct answer but chose a language in the same language group (i.e. Swedish instead of Danish is clearly a better choice than French).

As a second example, we turn to the case of Spanish and French, two of the best identified non-native accents. The distribution across the identifying countries conveys very symmetrical patterns (Table 4 and Table 5). The Spanish accent was correctly identified by 412 out of the 785 respondents, and the French one by 566 . Clear differences can be found in the identification competence of the different identifiers. For example, the French and Spanish are respectively better in recognizing their own accents than each other's. Additionally, the Belgian Dutch respondents are notably better at recognizing the French accent than at recognizing the Spanish accent.

\begin{tabular}{|l|c|c|c|}
\hline identified = FR & correct & not.corr & percentage correct \\
\hline FR & 98 & 0 & $100.0 \%$ \\
\hline NL & 81 & 17 & $82.7 \%$ \\
\hline BE & 76 & 19 & $80.0 \%$ \\
\hline SW & 52 & 16 & $76.5 \%$ \\
\hline GE & 72 & 27 & $72.7 \%$ \\
\hline PL & 67 & 32 & $67.7 \%$ \\
\hline SP & 61 & 30 & $67.0 \%$ \\
\hline DM & 59 & 76 & $43.7 \%$ \\
\hline
\end{tabular}

Table 4. Scores of correct identification of the French accent

\begin{tabular}{|l|c|c|c|}
\hline identified = SP & correct & not.corr & percentage correct \\
\hline SP & 90 & 1 & $98.9 \%$ \\
\hline SW & 43 & 25 & $63.2 \%$ \\
\hline NL & 59 & 40 & $59.6 \%$ \\
\hline GE & 54 & 44 & $55.1 \%$ \\
\hline BE & 51 & 44 & $53.7 \%$ \\
\hline PL & 42 & 56 & $42.9 \%$ \\
\hline FR & 34 & 64 & $34.7 \%$ \\
\hline
\end{tabular}




\begin{tabular}{|l|l|l|l|}
\hline DM & 39 & 97 & $28.7 \%$ \\
\hline
\end{tabular}

Table 5. Scores of correct identification of the Spanish accent

Various explanations can be thought of to explain these patterns. In the next section, we discuss which of these come into play in our multifactorial analyses, how we operationalized these variables and finally how we proceeded with the analyses.

\section{Multifactorial analysis: design}

How can the relative but general identificational agility of the Belgians and the Dutch, the Germans and the Swiss be explained? Is it due to the fact that these countries are located in central Europe, surrounded by many other countries and languages that provide them with more exposure to language variation than the rest? Would it have to do with citizens who watch TV in the original undubbed version, or travel more than their southern or northern peers? In this section, we describe the multifactorial analyses (mixed effects regression analysis, regression tree and random forest) that were carried out in order to try to address these questions. This section describes the variables included in the study and the analytic procedure followed.

\subsection{Response variable}

The dependent variable in this study is correct identification by an identifier of a given identified (stimulus). Crucially, the native accents are excluded from the analysis for two reasons: (1) we consider the question, in a fully symmetrical design, to what extent Continental European speakers recognize each other's L2 English accents; (2) the US accent 
serves as input in the operationalization for two of the predictor variables, which would lead to circularity when also included as response. In a similar reasoning, we exclude the identifications of respondents' own accent variety, which will also be used in the operationalization of one of the predictors below. Overall, we thus arrive at a database (in the strict version of the identifications) containing 1382 correct identifications and 4092 incorrect identifications for 785 respondents

\subsection{Predictor variables}

In aiming to explain the distribution of correct and incorrect classifications by respondents, a number of predictor variables are included: socio-economic status and gender, familiarity with English, size of the respondent's language, size of the stimulus language, the geolinguistic relation between stimulus language and respondent language, and the degree of accentedness of the stimulus. We describe the implementation of these variables below.

First, we included information on parental socio-economic status. In the survey administered after the experiment, respondents listed the profession of mother and father. Based on this information, a scale was implemented to operationalise parental socioeconomic status, containing the following five levels: higher mangerial and professional occupations (large employers, higher managerial occupations, higher profesional occupations such as university teachers); lower managerial and profesional occupations such as school teachers); intermediate occupations and small-scale employers such as autonomous workers, café owners etc.), lower supervisory and technical occupations (preuniversity studies of 1-3 years such as nurses etc.); routine occupations (white collar 
workers, transportation, warehousing, cashiers, shop assistants) and semi-routine occupations (seasonal fishermen, gardeners); long-term unemployed (including housewives). On the basis of the frequency distribution of the data, the factor was reorded as a ternary factor, by taking the upper two and the lower two levels together: respondents with parents with a low socio-economic status ("SES.low" in the analyses below; 172 respondents), respondents with parents with an average socio-economic status ("SES.average"; 248 respondents) and respondents with parents with a high socio-economic status ("SES.high"; 365 respondents).

Next, it is reasonable to expect that the more familiar language users are with English, the higher their identification competence will be. This familiarity with the English language received two different implementations. The factor "EL1.ID.nrCorr" measures familiarity with native Englishes ("EL1") in terms of the number of correct identifications per respondent of the four native English accents in the experiment (see Table 6).

\begin{tabular}{|l|l|}
\hline Number of correct EL1 identifications & N respondents \\
\hline 0 & 26 \\
\hline 1 & 90 \\
\hline 2 & 169 \\
\hline 3 & 257 \\
\hline 4 & 243 \\
\hline
\end{tabular}

Table 6. Number of correct EL1 identifications

The second operationalization of familiarity with the English language concerns a proxy for exposure to native English(es) in the media ("EL1.mediaExp"), determined in terms of 
dominant translation practices in the relevant countries. Thus, we distinguish between subtitling dominant countries (Denmark, The Netherlands, Belgium, Poland), versus countries with a strong dubbing tradition (France, Switzerland, Germany, and Spain).

With regard to the size of the languages involved in the experiment, big languages are considered to be Spanish, French, and (German) German, while the others are small(ish). The factor is included both for the respondents' language ("respSizeLang"), and for the stimulus language ("stimSizeLang"). The rationale for incorporating this variable is the assumption that smaller languages have a bigger interest in getting acquainted with other languages, whereas at the same time, bigger languages will be more readily encountered by others.

Next, the geolinguistic relationship between the stimulus and the respondent language is taken into account in the form of a ternary variable. A first option is that stimulus and response are close relatives, i.e. they belong to the same branch in the family tree (such as Danish, Dutch and German as Germanic languages). A second option is neighbouring languages, i.e. when the stimulus language does not belong to the close language family of the respondent language but is geographically adjacent (such as the situation holding between French and Belgian Dutch). A third option is then "no relationship", which refers to stituations were both languages are geographically distant and linguistically remote (such as Danish and Polish). Inclusion of this parameter is motivated by the assumption that both geographical proximity and linguistic kinship may enhance recognition. Table 7 provides an overview of the attested relationships. 


\begin{tabular}{|l|l|l|l|l|l|l|l|l|}
\hline & respBE & respDM & respFR & respGE & respNL & respPL & respSP & respSW \\
\hline stimBE & & family & neighbour & family & family & norel & norel & family \\
\hline stimDM & family & & norel & family & family & norel & norel & family \\
\hline stimFR & neighbour & norel & & neighbour & norel & norel & family & neighbour \\
\hline stimGE & family & family & neighbour & & family & neighbour & norel & family \\
\hline stimNL & family & family & norel & family & & norel & norel & family \\
\hline stimPL & norel & norel & norel & neighbour & norel & & norel & norel \\
\hline stimSP & norel & norel & family & norel & norel & norel & & norel \\
\hline stimSW & family & family & neighbour & family & family & norel & norel \\
\hline
\end{tabular}

Table 7. Overview of geolinguistic relationship between identifier and identified

The following parameter is degree of accentedness of the stimulus, which we add based on the recognition that not all stimulus fragments may be exactly equally typical for their accent, in spite of the precautions that were taken in selecting the stimuli (see above). As a proxy for direct phonetic measurement of accentedness (which would require an elaborate production study), we operationalize degree of accentedness in terms of the selfidentification scores of the various respondent groups, compared to their identification of the US fragment as the most focal accent. The motivation for this approach rests on the (admittedly somewhat tentative) assumption that if a country has difficulty recognizing its own accent, the stimulus in question is probably more weakly accented. At the same time, to take into account that some groups might be better or worse identifiers overall, we compare to their identification of the most commonly identified accent, i.e. the American accent is treated as a baseline, by calculating the percentage difference between identification of own accent and the US accent. These scores (listed in Table 8) are then transformed into an ordinal variable with three levels: "strongly" accented stimuli are 
French and Spanish, "averagely" accented stimulus are the Swiss German, the German, the Belgian Dutch and the Dutch, and "weakly" accented stimuli are the Danish and the Polish.

\begin{tabular}{|l|c|c|c|}
\hline Identifier & $\begin{array}{c}\text { \% correct self- } \\
\text { identification }\end{array}$ & $\begin{array}{c}\text { \% correct identification } \\
\text { of US accent }\end{array}$ & $\begin{array}{c}\text { \% increase } \\
\text { US to L1 }\end{array}$ \\
\hline FR & 100.0 & 63.0 & 58.73 \\
\hline SP & 98.9 & 70.3 & 40.68 \\
\hline SW & 98.6 & 92.6 & 6.48 \\
\hline GE & 96.0 & 90.9 & 5.61 \\
\hline BE & 97.9 & 93.8 & 4.37 \\
\hline NL & 100.0 & 97.0 & 3.09 \\
\hline DM & 77.4 & 84.9 & -8.83 \\
\hline PL & 61.6 & 90.9 & -32.23 \\
\hline
\end{tabular}

Table 8.calculation of proxy for accentedness of the identified (stimulus)

\subsection{Analytic procedure}

The impact of the predictors (see Table 9 for an overview of parameters and abbreviations) on the response variable (correct identification of the different stimuli) is tested through three analyses. First, a mixed effect regression analysis is conducted, which adds test subject (nested in country) and the stimulus fragment as random variables. This helps us account for the autocorrelation patterns that inevitably occur in our data due to the repeated measure (every respondent is subjected to more than one stimulus, and every stimulus is rated by more than one respondent). Second, we include a conditional inference tree (with identifier and identified included as variable), a technique that allows us to study the interplay of and interactions between the different predictor variables in explaining variation in the response. Finally, a random forest is presented that shows the relative 
contribution of these predictors in explaining the attested variation: how strong is the effect of the individual parameters when taking their combined effect into account?

\begin{tabular}{|l|l|}
\hline Predictor variable & Abbreviations \\
\hline SES of the respondent's parents & SES: \\
& SES.low, SES.average, SES.high \\
\hline Familiarity with the English language: & EL1.ID.nrCorr: \\
Number of correctly identified EL1 stimuli & $0,1,2,3,4$ (Helmert coding) \\
\hline Familiarity with the English language: & EL1.mediaExp: \\
Media exposure & dubbing, subtitling \\
\hline Size of the respondents' language & resp.sizeLang: \\
& largeLang, smallLang \\
\hline Size of the stimulus language & stim.sizeLang: \\
& largeLang, smallLang \\
\hline Geolinguistic relationship between the & kinship: \\
identifier and the identified & family, neighb, norel \\
\hline Accentedness of the stimulus & accentedness: \\
& weaklyAcc, averAcc, stronglyAcc \\
\hline
\end{tabular}

Table 9.overview of predictor variables

\section{Multifactorial analysis: results}

\subsection{Mixed effect regression model}

The results of the regression analysis are as in Table 10 and Table 11 . Table 10 shows the effects for the levels of the predictors, while Table 11 represents an analysis of deviance (the mixed-effect counterpart of anova) indicating the relative contribution of each of the predictors as a whole. For each of the categorical variables, one of the levels is taken as the intercept, with which all other levels are compared (reference levels: "weaklyAcc" for accentedness, "family" for kinship, "SES.high" for SES). An exception concerns the parameter "EL1.ID.nrCorr". To take the ordinal nature of this variable (ranging from 0 to 4 
correct identifications of English L1 varieties) into account, Helmert coding is used for this variable in the regression analysis. This means that, instead of simply comparing each level of the predictor to the intercept, we compare each level with the mean of the previous levels taken together.

The technical diagnostics for the model are good. As shown in Table 12, the reduction in standard deviation around the random effects (as an indication of the extent to which the fixed effects can diminish the messiness of the random effects; Baayen 2008) is fine. The random effects for Country and Stimulus are additionally normally distributed. The random effects for respondent nested in Country are not normally distributed according to the Shapiro-Wilk test ( $\mathrm{p}$ 0.0003), but upon inspection, the distribution appears to be clean enough to pass. All in all, this is a decent and reliable model with intuitive results.

The outcome conforms to what would be the spontaneous hypotheses: "strong" accentedness enhances identification, geolinguistic distance diminishes identification, familiarity with L1 English enhances identification, and a low socio-economic background diminishes identification. In other words, European students are better at identifying European L2 English accents if the accents are perceived as strong, if they are familiar with L1 English, and if they are familiar with the native language of the L2 accents.

$\begin{array}{lrrrr} & \text { Estimate } & \text { Std. Error } & \text { z value } & \operatorname{Pr}(>|z|) \\ \text { (Intercept) } & -2.25779 & 0.4739 & -4.764 & <0.00001 * * * \\ \text { accentedness-- averAcc } & 0.47911 & 0.50774 & 0.944 & n \text { nS }\end{array}$




$\begin{array}{lrrrr}\text { accentedness-- stronglyAcc } & 3.00131 & 0.58219 & 5.155 & <0.00001 * * * \\ \text { kinship-- neighb } & -0.54945 & 0.15273 & -3.597 & <0.001 * * * \\ \text { kinship-- norel } & -0.70099 & 0.11779 & -5.951 & <0.00001 * * * \\ \text { EL1.ID.nrCorr-- helm1 } & -0.0634 & 0.15997 & -0.396 & \mathrm{NS} \\ \text { EL1.ID.nrCorr-- helm2 } & 0.12753 & 0.06284 & 2.03 & 0.04 * \\ \text { EL1.ID.nrCorr-- helm3 } & 0.13806 & 0.03431 & 4.024 & <0.0001 * * * \\ \text { EL1.ID.nrCorr-- helm4 } & 0.1353 & 0.02316 & 5.841 & <0.00001 * * * \\ \text { SES-- SES.average } & 0.10117 & 0.0904 & 1.119 & \mathrm{NS} \\ \text { SES-- SES.low } & -0.27426 & 0.10887 & -2.519 & 0.01 *\end{array}$

Table 10. Mixed effect regression analysis

Chisq Df $\operatorname{Pr}(>$ Chisq)

Accentedness

$32.7982<0.00001 * * *$

kinship.tern

$38.0942<0.00001 * * *$

EL1.ID.nrCorr.helm

$45.5684<0.00001 * * *$

SES

$10.68720 .005^{* *}$

Table 11. Analysis of Deviance (Type II Wald chisquare tests) for the mixed effect regression

analysis

\begin{tabular}{lccc}
$\begin{array}{l}\text { Random } \\
\text { effects }\end{array}$ & $\begin{array}{c}\text { SD null model } \\
\text { (only including } \\
\text { random effects) }\end{array}$ & $\begin{array}{c}\text { SD } \\
\text { fitted model }\end{array}$ & $\begin{array}{c}\text { reduction } \\
\text { (1-(SD Fitted/SD Null)) }\end{array}$ \\
\hline Id.Enc:Country & 0.4448 & 0.3568 & 0.198 \\
Country & 0.7751 & 0.5811 & 0.250 \\
Stimulus & 1.2488 & 0.5694 & 0.544 \\
\hline
\end{tabular}

Table 12. diagnostics

\subsection{Conditional inference tree and random forest}


The mixed effects regression model does not tell us how the significant predictors work in the case of the individual languages. Inspection of the BLUPS (the best linear unbiased predictors, i.e. estimates for the random effects) could help us out, though a more interesting perspective is offered by conditional inference trees. A notable benefit of this technique is that it reveals the interactions between different predictors, specifically fit for datasets suffering from "small n, large p"-issues (see Tagliamonte \& Baayen 2012, and e.g. Szmrecsanyi et al. 2016, Zenner \& Van de Mieroop forthcoming). We additionally present a random forest, which is a robust alternative to anova's, meant to gauge the relative contribution of a set of predictor variables.

The tree represented in Figure 2 includes the significant predictors from the regression analysis, together with respondents' language (Country) and stimulus language (Stimulus). The predictive power of the tree is $82.7 \%$, compared to a baseline of $74.7 \%$. To facilitate the interpretation of the tree, the following may be kept in mind. First, successive splits in the tree identify the factors that contribute most to explaining the variation in the result. Second, the bar plots at the bottom represent the success rates, i.e. the degree of correct identification. Third, because we are looking at the combined effect of various factors, any given language may appear in various positions on the bottom line of the tree, that is to say, several groups of combined factors may lead to a certain level of identification for that language. Given these 'reading instructions', we can now recognize several groupings in the tree. 
A first group (node 25) consists of languages with relatively high identificational success rates, and for which the stimulus as such (rather than for instance the identifiers' language) is the dominant influence on identification. This applies to French and Spanish as "heavily" accented and easily recognizable languages. A second and third group are characterized by low success rates, which may result either from the weakness of the identifiers (this applies to the Danes, the French, the Poles, and the Spaniards, node 20), or from the fact that we are dealing with minor, less familiar target languages (Belgian Dutch, Danish, Swiss German, Polish, node 4). A fourth group (node 11) has high success rates, where basically, the speakers of the West Germanic languages identify two specific West Germanic languages, viz. German and (Netherlandic) Dutch.

Figure 3 contains a random forest that shows the relative contribution of the parameters included for selection in the conditional inference tree presented in Figure 2 (with dots on the right side of the dotted line being significant contributors; the further to the right, the higher the relative importance of the variable). The tree itself includes the predictors stimulus, country, size of the stimulus language, kinship between stimulus and response and number of correct identified EL1 fragments. These parameters are also considered significant contributors to explaining the variation in the response when looking at the random forest. Two other predictors are important, namely accentedness (with a high relative importance) and size of the respondent's language. 


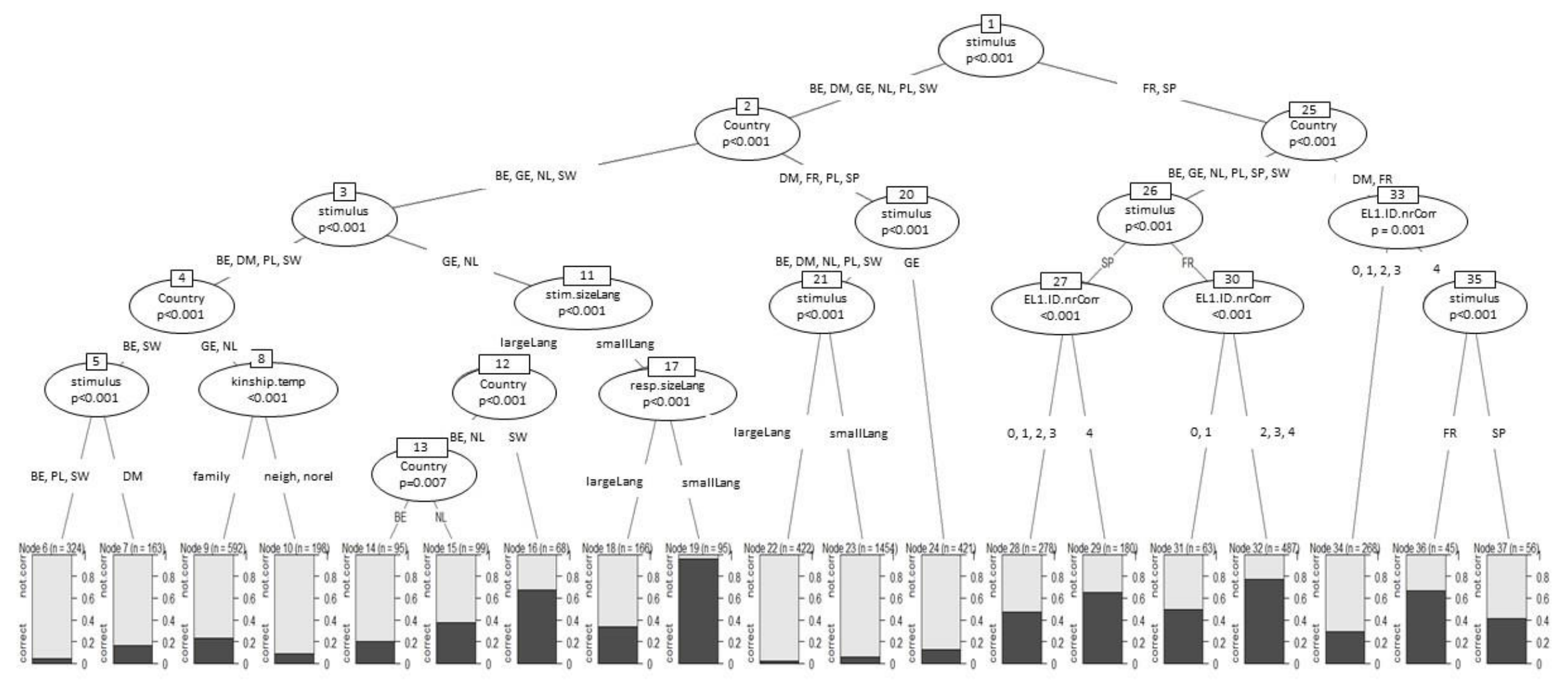

Figure 2. Conditional inference tree with predictors and identifier (country) and identified (stimulus) as predictors 


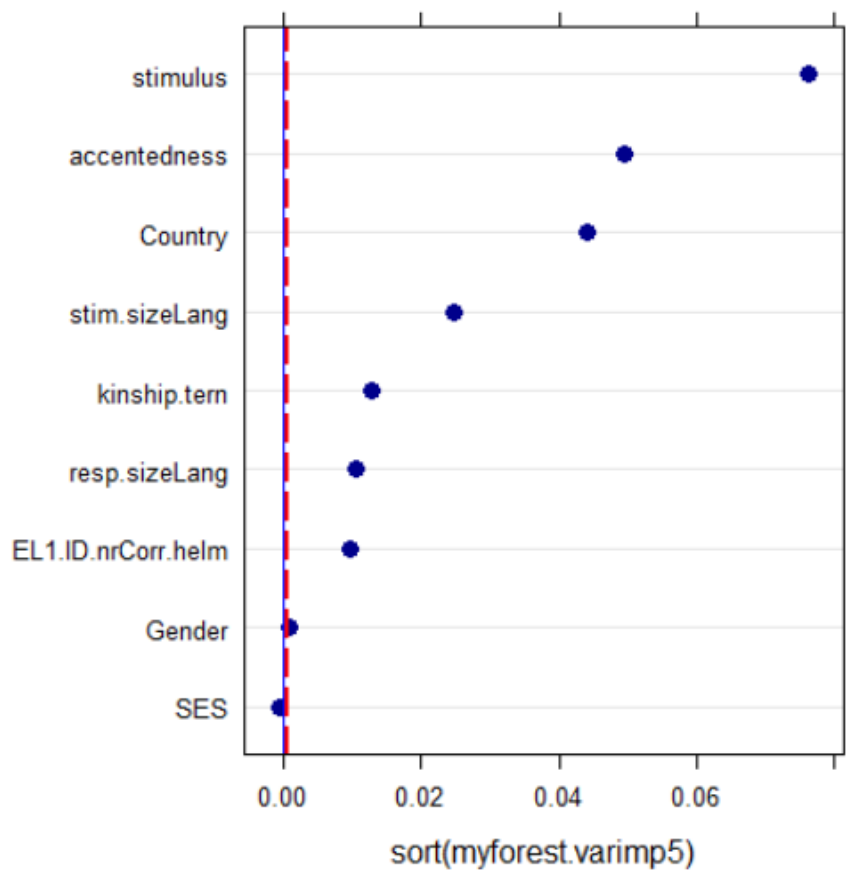

Figure 3. Random forest 


\section{Conclusion}

Overall, the quantitative analysis shows that L2 English accent recognition is determined by the interplay of various factors, specifically the perceived degree of accentedness of a stimulus, familiarity with L1 English, and familiarity with the native language of the L2 accent. These factors work in diverse combinations and strengths for different groups of languages, or more precisely, for the various pairs of respondent and stimulus languages in the data. Identifying these determining influences leads to the formulation of a number of questions for further research.

First, we note that the speakers of some languages are less successful identifiers, but we need to deepen our knowledge of the origins of that weaker performance. Specifically, what are the determinants of familiarity with L1 accents: schooling, contacts and experience, media exposure - and crucially, which media?

Second, we observe that the degree of accentedness of stimuli contributes to their identifiability, but it will have to be investigated how differently accentedness is perceived for different languages and different phonetic features: shibboleths are likely to have a stronger effect than less stereotyped forms, and languages with a larger number of shibboleths are likely to be perceived as more accented. In other words, how can we distinguish between the accentedness of the specific stimulus fragments and the overall markedness of the languages? 
And third, we have achieved a better understanding of the conditions under which L2 accents are identified, but there is an obvious attitudinal dimension to be added: how are L2 accents evaluated, and to what extent do identification and evaluation interact?

\section{References}

Baayen, R. H. (2008). Analyzing linguistic data: A practical introduction to statistics using $R$. Cambridge, U.K.: Cambridge University Press.

Bybee, J. (1999). Phonology and language use. Cambridge: Cambridge University Press.

Carrie, E. \& McKenzie, R. M. (2017). American or British? L2 speakers' recognition and evaluations of accent features in English. Journal of Multilingual and Multicultural Development 38, 6.

Cooper, R. L. (1975). Introduction to language attitudes II. International Journal of the Sociology of Language 6, 5-9.

Dewey, M. (2011). Accommodative ELF talk and teacher knowledge. In A. Archibald, A. Cogo \& J. Jenkins (Eds.), Latest Trends in ELF Research (pp. 205-228). Newcastle upon Tyne: Cambridge Scholars Publishing.

Eisenchlas, S. A. \& Tsurutani, C. (2011). You sound attractive! Perceptions of accented English in a multilingual environment. Australian Review of Applied Linguistics 34, 2, 216-236.

Firth, A. (2009). The lingua franca factor. Intercultural Pragmatics 6 (2), 147-170.

Garrett, P., Coupland, N. \& Williams, A. (2003). Investigating language attitudes: Social meanings of dialect, ethnicity, and performance. Cardiff: University of Wales Press. 
Geeraerts, D. (1983). Prototype theory and diachronic semantics: A case study. Indogermanische Forschungen 88, 1-32.

Geeraerts, D. (1985). Paradigm and paradox. Explorations into a paradigmatic theory of meaning and its epistemological background. Leuven: Universitaire Pers.

Geeraerts, D. (1989). Prospects and problems of prototype theory. Linguistics 27 (4), 587-612.

Geeraerts, D. (2003). Cultural models of linguistic standardization. In R. Dirven, R. Frank \& M. Pütz (Eds.) Cognitive models in language and thought. Ideology, metaphors and meanings (pp. 25-68). Berlin, New York: Mouton de Gruyter.

Geeraerts, D., Grondelaers, S., \& Speelman, D. (1999). Convergentie en divergentie in de Nederlandse woordenschat. Amsterdam: Meertens Instituut.

Geeraerts, D., Kristiansen, G. \& Peirsman, Y. (Eds.) (2010). Advances in cognitive sociolinguistics. Berlin, New York: Mouton de Gruyter.

Giles, H. \& Rakić, T. (2014). Language attitudes: the social determinants and consequences of language variation. In T. M. Holtgraves (Ed.), The Oxford handbook of language and social psychology. Oxford: Oxford University Press.

Graddol, D. (1997) The future of English? London: The British Council.

Grondelaers, S. \& Kristiansen, T. (2013). On the need to access deep evaluations when searching for the motor of standard language change. In T. Kristiansen \& S. Grondelaers (Eds.), Language (De)standardisations in Late Modern Europe: Experimental studies, (pp. 952). Oslo: Novus Press. 
House, J. (2009). Introduction: The pragmatics of English as a Lingua Franca. Intercultural Pragmatics 6, 2, 141-145.

Jarvella, R.J., E. Bang, A.L. Jakobsen \& Mees, I.M. (2001). Of mouths and men: non-native listeners' identification and evaluation of varieties of English. International Journal of Applied Linguistics 11 (1), 37-56.

Jenkins, J. (2000). The phonology of English as an International Language. Oxford: Oxford University Press.

Jenkins, J. (2007). English as a Lingua Franca: Attitude and identity. Oxford: Oxford University Press.

Jenkins, J. (2009). (Un)pleasant? (In)correct? (Un)intelligible? ELF speakers' perceptions of their accents. In A. Mauranen \& E. Ranta (eds.), English as a Lingua Franca: Studies and findings (pp. 10-36). Newcastle upon Tyne: Cambridge Scholars Publishing.

Jenkins, J., W. Baker \& Dewey, M. (2018). The Routledge Handbook of English as a Lingua Franca. London: Routledge.

Jurado Bravo, M. A. \& G. Kristiansen. (To appear). How to measure foreign accentedness and intelligibility in an objective manner. Edited volume in Language Variation - European Perspectives (John Benjamins).

Kachru, B. B. (1985). Standards, codification, and sociolinguistic realism: The English language in the outer circle. In R. Quirk \& H. Widdowson (Eds.) English in the world: Teaching and learning the language and the literature. Cambridge: Cambridge University Press. Kachru, B. B. (Ed.). (1992). The other tongue. Urbana: University of Illinois Press. 
Kirkpatrick, A. (2014). World Englishes. In C. Leung \& B. Street (eds.), The Routledge Companion to English Studies. London: Routledge.

Kristiansen, G. (2001). Social and linguistic stereotyping: A cognitive approach to accents. Estudios Ingleses de la Universidad Complutense 9, 129-145.

Kristiansen, G. (2003). How to do things with allophones: Linguistic stereotypes as cognitive reference points in social cognition. In R. Dirven, R. Frank \& M. Pütz (Eds.), Cognitive models in language and thought. Ideology, metaphors and meanings (pp. 69-120). Berlin, New York: Mouton de Gruyter.

Kristiansen, G. (2006) Towards a usage-based cognitive phonology. International Journal of English Studies, 6(2): 107-140.

Kristiansen, G. (2008). Style shifting and shifting styles: A socio-cognitive approach to lectal variation. In G. Kristiansen \& R. Dirven (Eds.), Cognitive sociolinguistics: Language variation, cultural models, social systems (pp. 45-88). Berlin, New York: Mouton de Gruyter.

Kristiansen G. (2010). Lectal acquisition and linguistic stereotype formation: an empirical study. In D. Geeraerts, G. Kristiansen, \& Y. Peirsman (Eds.) Advances in cognitive sociolinguistics. Berlin, New York: Mouton de Gruyter.

Lambert, W. E., Hodgson, R.C. Gardner, R. C. \& Fillenbaum, S. (1960). Evaluational reactions to spoken language. Journal of Abnormal and Social Psychology, 60, 44-51.

Lindemann, S. (2005). Who speaks "broken English"? US undergraduates' perceptions of nonnative English. International Journal of Applied Linguistics 15 (2), 187-212. 
Marzo, S., E. Zenner \& Van de Mieroop, D. (Forthc). The social meaning of sibilant palatalization in urban vernacular speech in Flanders: a Prototype Approach. In E. Zenner, A. Backus \& E. Winter-Froemel (eds), Cognitive Contact Linguistics: Placing usage, meaning and mind at the core of contact-induced variation and change. Berlin, Boston: Mouton.

McKenzie, R.M. (2008). Social factors and non-native attitudes towards varieties of spoken English: a Japanese case study. International Journal of Applied Linguistics 18 (1), 63-88.

McKenzie, R. M. (2015). The sociolinguistics of variety identification and categorisation: free classification of varieties of spoken English amongst non-linguist listeners. Language Awareness 24 (2), 150-168.

Modiano, M. (1999). International English in the global village. English Today, 15, 22-28.

Pickering, L. (2006). Current research on intelligibility in English as a Lingua Franca. Annual Review of Applied Linguistics. 26, 219-233.

Polzenhagen, F. \& Dirven, R. (2008). Rationalist or romantic model in globalisation. In G. Kristiansen and R. Dirven (eds.), Cognitive Sociolinguistics. Language variation, cultural models, social systems (pp. 237-299). Berlin, New York: Mouton de Gruyter.

Polzenhagen, F. \& Xiaoyan, X. (2015). Language, Culture and Prototypicality. In F. Sharifian (ed.), Routledge Handbook of Language and Culture (pp. 253-269). New York: Routledge. Preston, D. (Ed.). (1999). Handbook of perceptual dialectology I. Amsterdam: Benjamins. Purnell, T., Idsardi, W., \& Baugh, J. (1999). Perceptual and phonetic experiments on American English dialect identification. Journal of Language and Social Psychology 18 (1), 10-30. 
Rosch, E. (1973). On the internal structure of perceptual and semantic categories. In T. E. Moore (Ed.) Cognitive development and the acquisition of language (pp. 111-144). New York: Academic Press.

Rosch, E. (1978). Principles of categorization. In E. Rosch \& B. B. Lloyd (Eds.) Cognition and categorization (pp. 27-48). Hillsdale, NJ: Lawrence Erlbaum.

Rosseel, L. (2017). New approaches to measuring the social meaning of language variation. Exploring the Personalized Implicit Association Test and the Relational Responding Task. Unpublished PhD dissertation defended in September 2017, The University of Leuven.

Scales, J., A. Wennerstrom, D. Richard \& Wu, S.H. (2006). Language Learners' Perceptions of Accent. TESOL Quarterly 40 (4), 715-738.

Seargeant, P. (2017). The symbolism of English on the Brexit battleground. World Englishes 36 (3), 356-359.

Seidlhofer, B. (2002) Habeas corpus and divide et empera: "global" English and applied linguistics. In K. Spellman Miller \& P. Thompson (eds.), Unity and diversity in language use (pp. 198-220). London: BAAL and Continuum.

Seidlhofer, B. (2004) 10. Research perspectives on teaching English as a Lingua Franca. Annual Review of Applied Linguistics 24, 209-239.

Speelman, D., Grondelaers, S., \& Geeraerts, D. (2003). Profile-based linguistic uniformity as a generic method for comparing language varieties. Computers and the Humanities 37, 317337. 
Speelman, D., Heylen, K., \& Geeraerts, D. (2018). Mixed-effects regression models in linguistics. New York: Springer.

Szmrecsanyi, B., J. Grafmiller, B. Heller \& Röthlisberger, M. (2016). Around the world in three alternations Modeling syntactic variation in varieties of English. English World-Wide 37 (2), 109-137.

Tagliamonte, S. \& Baayen, H. R. . (2012). Models, forests, and trees of York English: Was/were variation as a case study for statistical practice. Language Variation and Change 24 (2), 135178.

Taylor, J. R. (1989). Linguistic categorisation. Prototypes in linguistic theory. Oxford: Clarendon Press.

Yano, Y. (2001) World Englishes in 2000 and beyond. World Englishes 20.2: 119-30.

Young, T.J. \& Walsh, S. (2010). Which English? Whose English? An investigation of 'non-native' teachers' beliefs about target varieties. Language, Culture and Curriculum 23 (2), 123-137.

Zenner, E., D. Van De Mieroop. (forthc.). The alternation between standard and vernacular by Belgian Dutch parents in child-oriented control acts. To appear in A. Ghimenton, A. Nardy, J. Chevrot (eds.), Sociolinguistic Variation and Language Acquisition across the Lifespan. Amsterdam: Benjamins.

Zhang, W. \& Hu, G. (2008) Second Language Learners' Attitudes Towards English Varieties. Language Awareness 17 (4), 342-347. 